\title{
Shoulder Impingement
}

\author{
Catherine E. Tagg, $\mathrm{FRCR}^{1}$ Alastair S. Campbell, FRCR ${ }^{2}$ Eugene G. McNally, $\mathrm{FRCR}^{3}$
}

${ }^{1}$ Nevill Hall Hospital, Aneurin Bevan Health Board, Abergavenny, United Kingdom

${ }^{2}$ Craigavon Area Hospital, Southern Health and Social Care Trust, Portadown, United Kingdom

${ }^{3}$ Nuffield Orthopaedic Centre, Oxford University Hospitals NHS Trust, Oxford, United Kingdom

Address for correspondence Eugene G. McNally, FRCR, Nuffield Orthopaedic Centre, Oxford University Hospitals NHS Trust, Old Road, Oxford, OX3 7LD, UK (e-mail: eugene.mcnally@gmail.com).

Semin Musculoskelet Radiol 2013;17:3-11.

\begin{abstract}
Keywords

- shoulder

- ultrasound

- impingement

This update examines recent articles and evidence for the role of ultrasound in the diagnosis and management of shoulder impingement syndromes and emphasizes its principal application in evaluation for external impingement. Shoulder ultrasound is commonly used as the initial investigation for patients with shoulder pain and suspected impingement. This is due to the high resolution of current ultrasound machines, wide availability, good patient tolerance, cost effectiveness, and, most importantly, its dynamic and interventional role.
\end{abstract}

Impingement is a clinical scenario of painful functional limitation of the shoulder, ${ }^{1}$ thought to be secondary to compression or altered dynamics that irritate and ultimately damage the tissues around the shoulder joint. Shoulder impingement is currently subdivided into external (subacromial) and internal impingement. External impingement is further subdivided into primary and secondary, and internal impingement into posterosuperior and anterosuperior (-Fig. 1).$^{2-8}$

\section{External Impingement}

The theory of external impingement syndrome was first proposed by Neer in 1972 to describe shoulder pain associated with varying degrees of chronic bursitis and partial- or full-thickness tears of the rotator cuff. ${ }^{7}$ However, this was before the advent of modern imaging, primarily ultrasound (US) and MR imaging. External/subacromial impingement occurs when the supraspinatus tendon and subacromialsubdeltoid (SASD) bursa are impinged between the humeral head, the acromion, and coracoacromial ligament. Early theories on etiology focused on anatomical abnormalities of the coracoacromial arch (-Fig. 2). However, there is growing evidence that scapular dysfunction may be more significant, especially in the patient $<40$ years of age.

\section{Etiology of Impingement}

Anatomical abnormalities of the arch have highlighted morphological variation in the acromion and acromioclavicular

Issue Theme Musculoskeletal Ultrasound Update; Guest Editor, Jon A. Jacobson, MD.

(AC) joint. The morphology of the acromion has been categorized into three types (type I flat, type II concave, and type III hooked). It has been suggested that the hooked type III configuration may predispose to external impingement. ${ }^{9}$ However, it is more likely that (unless the anatomical changes are gross) acromial changes are secondary rather than primary. Anterior and lateral downsloping of the acromion is also implicated in external impingement, particularly in tears of the supraspinatus tendon at its attachment. Acromioclavicular joint arthrosis, with osteophytes on the undersurface of the acromium, ${ }^{1}$ and os acromiale are both believed to be causative in external impingement but are not accurately assessed with US and require subacromial outlet radiographs or MR imaging for optimal visualization.

Functional abnormalities lead to external impingement by causing a relative decrease in the subacromial space due to glenohumeral instability or abnormal scapulothoracic movement. In other words, it is proximal displacement of the humeral head that causes impingement of the subacromial space against the coracoacromial arch rather than the reverse. These are encompassed within the term the SICK scapula syndrome (scapular malposition, inferomedial prominence, coracoid pain, scapular dyskinesis). ${ }^{9 a}$ The disturbed balance of forces between the rotator cuff muscles and the deltoid muscle leads to elevation of the humeral head and secondary impingement of the contents of the subacromial space on the coracoacromial arch. Abnormal shoulder biomechanics also contribute to glenohumeral instability, particularly the

Copyright @ 2013 by Thieme Medical Publishers, Inc., 333 Seventh Avenue, New York, NY 10001, USA. Tel: +1(212) 584-4662.
DOI http://dx.doi.org/ 10.1055/s-0033-1333908. ISSN 1089-7860. 


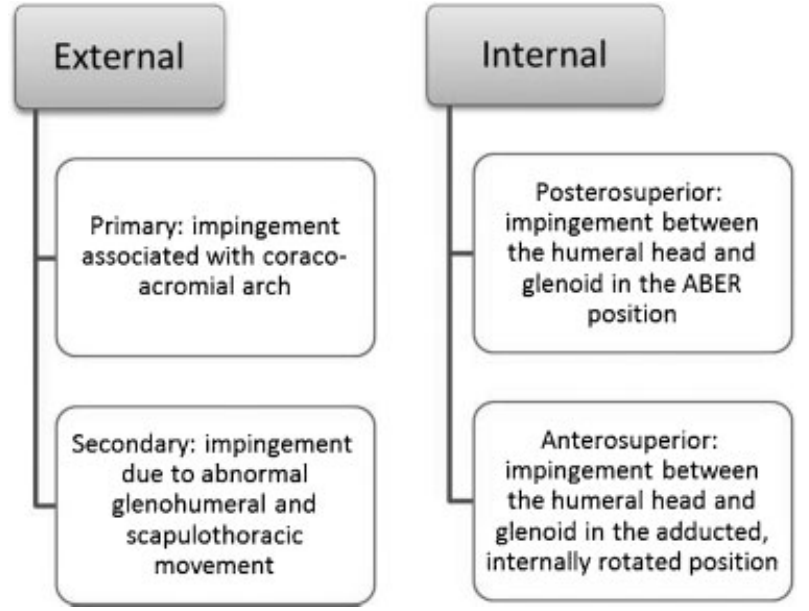

Fig. 1 Current definition of shoulder impingement. ABER, abducted and externally rotated.

defects more usually referred to as "micro instability" that are distinguished from the spectrum of joint hyperlaxity/ dislocation. Secondary external impingement is usually found in the younger age groups or in athletes involved in overhead or throwing activities.

Intrinsic factors of the rotator cuff tendons have also been implicated. These include a hypovascular "critical zone" within the tendon with subsequent ischemic changes and poor healing. However, this may represent tendon degeneration as part of the normal aging process. Tendon thickening with mucoid degeneration as a result of eccentric forces while in the overhead position leads to subsequent impingement on the coracoacromial arch due to the increased size of the tendon. ${ }^{4}$

Clinical examination and tests have been shown to be sensitive but nonspecific in their ability to differentiate

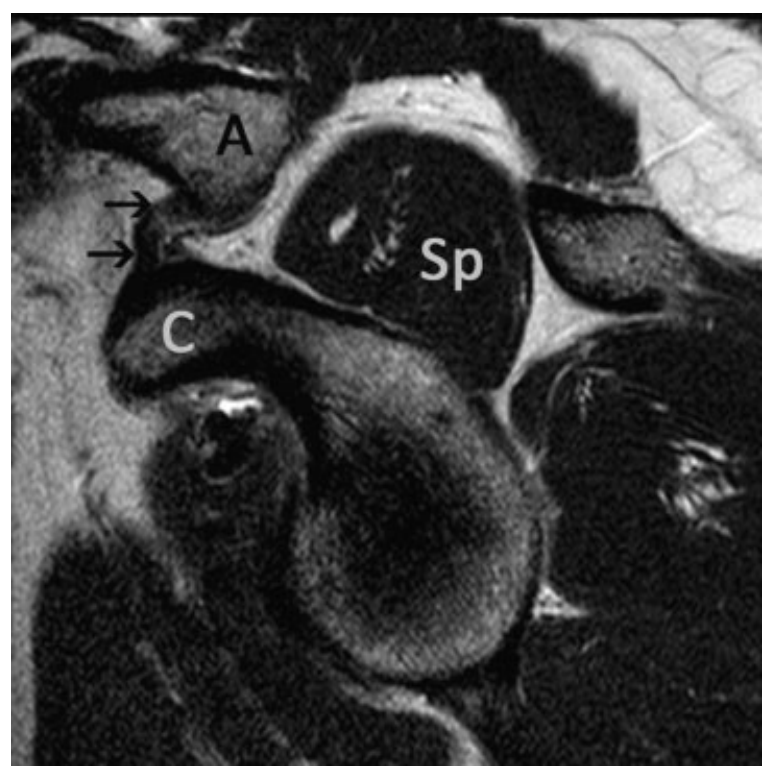

Fig. 2 Sagittal T2-weighted MRI of the shoulder demonstrates the coracoacromial arch. Coracoacromial ligament is shown (small arrows). A, acromion; C, coracoid; Sp, supraspinatus muscle. between shoulder impingement and other pathology. ${ }^{10} \mathrm{Im}$ aging is performed to identify pathology associated with impingement such as rotator cuff tears and to identify abnormalities that may be contributing to impingement.

\section{Ultrasound Findings in External/Subacromial Impingement}

The US findings in patients with external impingement are divided into changes in and around the bursa and abnormalities within the rotator cuff tendons. The SASD bursa is the largest bursa in the body covering the entire shoulder. The bursa acts as a joint between the rotator cuff and the overlying coracoacromial arch. The bursa is superficial to the rotator cuff tendons and deep to the deltoid muscle, coracoacromial ligament, and the acromion. The SASD is separated from the glenohumeral joint by the rotator cuff. The hypoechoic fluid within the bursa should not exceed $2 \mathrm{~mm}$ between the hyperechoic peribursal fat. ${ }^{6}$

\section{The Bursa and Coracoacromial Ligament}

Fluid within the SASD bursa and bursal thickening is easily identified with US, although care must be taken not to apply too much pressure with the transducer and underestimate the size or presence of bursal fluid ( $\mathbf{- F i g}$. 3). The most dependent segment of the bursa just distal to the greater tuberosity on longitudinal views of the rotator cuff should always be examined. The amount of fluid within the bursa should not measure greater than $2 \mathrm{~mm} .{ }^{11}$ The coexistence of glenohumeral joint and biceps tendon sheath fluid and subacromial-subdeltoid bursal fluid has been shown to be predictive of a rotator cuff tear. ${ }^{12}$ However, bursal fluid or thickening alone is not diagnostic of impingement. ${ }^{13}$

The coracoacromial ligament (CAL) can be visualized well with high-resolution US in both the transverse and

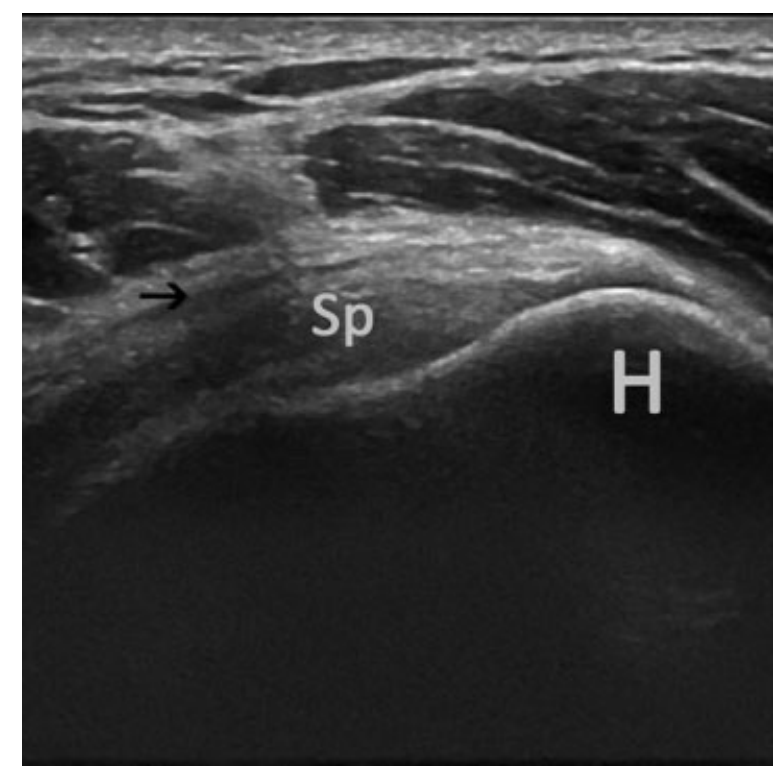

Fig. 3 US long axis over supraspinatus tendon shows fluid within the supraspinatus tendon and subacromial-subdeltoid bursa (arrow). $\mathrm{H}$, greater tuberosity of humerus; Sp, supraspinatus tendon. 
longitudinal planes (-Fig. 4). The CAL is seen as a straight or slightly convex fibrillar band in long axis passing between the coracoid and the tip of the acromion. The CAL is more difficult to visualize in short axis because it has similar echogenicity to the underlying peribursal fat and may only be seen as a notch in a distended bursa. The CAL forms the central aspect of the coracoacromial arch, where it acts as a focal cause of stenosis in subacromial impingement. ${ }^{7,14}$

US imaging of secondary external impingement involves recognition of subacromial space pathology secondary to variations in the size of the subacromial space. The subacromial space can be measured as the acromial humeral distance. Desmeules et al. found that the acromial humeral distance was reduced significantly in patients during active abduction compared with rest. The study also suggested that there was a reduction in the narrowing of the subacromial space with functional improvement following rehabilitation. ${ }^{15}$

Dynamic US assessment of the shoulder has gained popularity in the diagnosis of external impingement. One technique involves observing pooling of fluid within the subacromial-subdeltoid bursa or bunching of the bursa against the CAL with the arm in 60 degrees forward flexion, 60 degrees abduction, and internal rotation of the shoulder (-Fig. 5). The patient should be asked whether this maneuver reproduces or causes pain. Osseous impingement can also be observed when the humeral head is proximally migrated and the greater tuberosity is prevented from passing underneath the acromium. ${ }^{16}$ Reduction of the subacromial space with dynamic imaging was also shown in elite junior tennis players with scapular dyskinesia compared with controls. ${ }^{17}$

The relationship of the CAL with the subacromial bursa and rotator cuff tendons can also be assessed with dynamic imaging impingement tests. ${ }^{14}$ There may be degeneration and stiffening of the CAL with age, which leads to less displacement of the CAL with shoulder motion causing

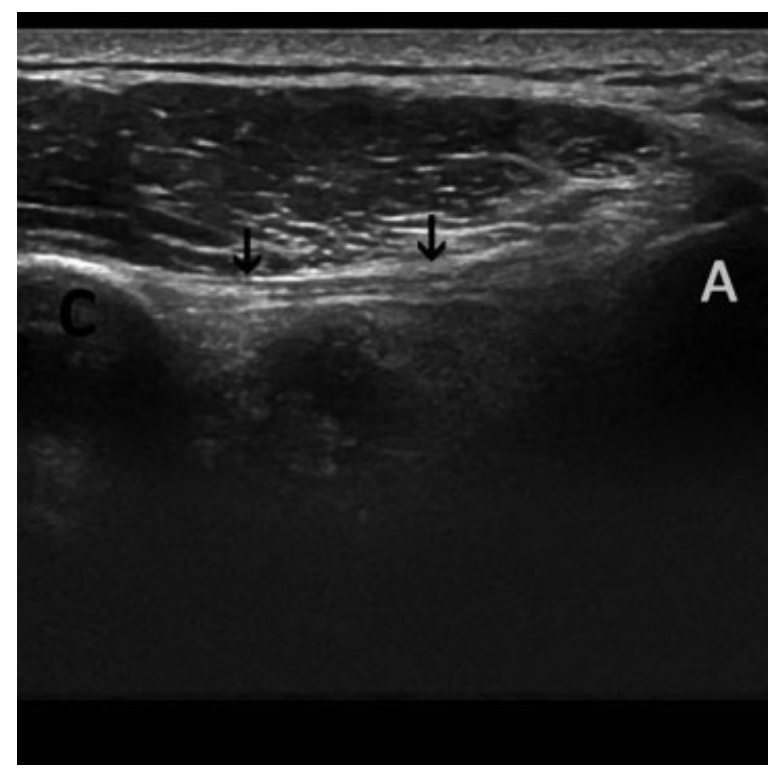

Fig. 4 Longitudinal US image of coracoacromial ligament (arrows). A, acromion; C, coracoid.
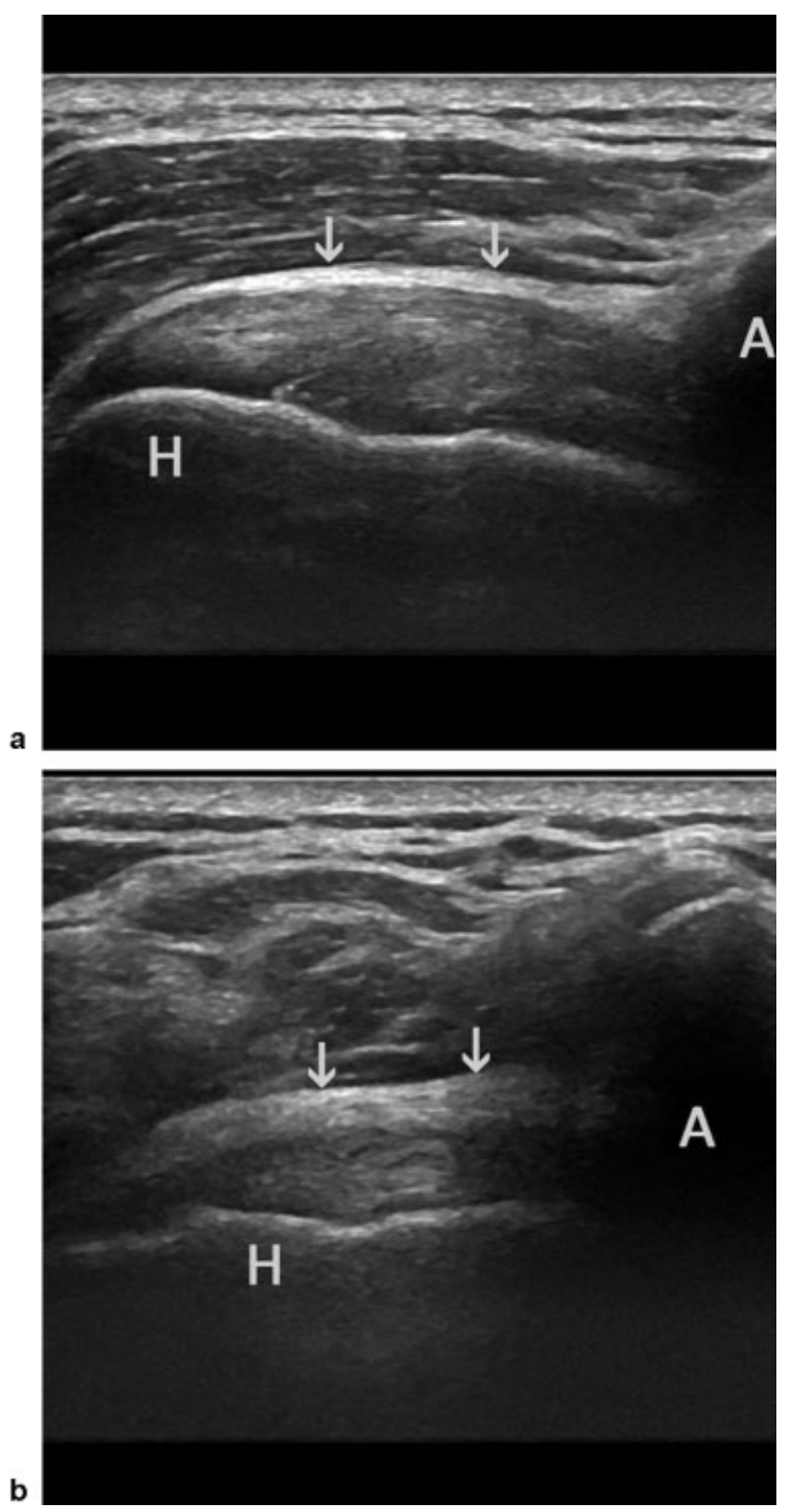

Fig. 5 Long axis US over supraspinatus (a) at rest and (b) abduction showing bunching of the supraspinatus tendon and subacromialsubdeltoid bursa (arrows) under the acromion (A). $\mathrm{H}$, greater tuberosity of humerus.

impingement. ${ }^{17 a}$ Wang et al described their method of measuring CAL length $(31.2 \pm 2.99 \mathrm{~mm})$, thickness $(1.97 \pm 0.49$ $\mathrm{mm})$, and distance between the CAL and humeral head $(7.48 \pm 1.89 \mathrm{~mm})$ in 25 young, slim, and healthy volunteers. They also quantified the effects of impingement tests on upward bulging of the CAL contour, paving the way for further research in this area. ${ }^{14}$

The appearance of the bursa in normal individuals has received some attention, but a detailed comparative study is lacking. No significant difference in the thickness of bursal fluid was shown between asymptomatic volunteers and symptomatic patients by Daghir. ${ }^{13}$ Pooling of fluid has been shown in asymptomatic volunteers and in the contralateral asymptomatic shoulder; however, this may represent subclinical abnormality. ${ }^{13,16}$ 


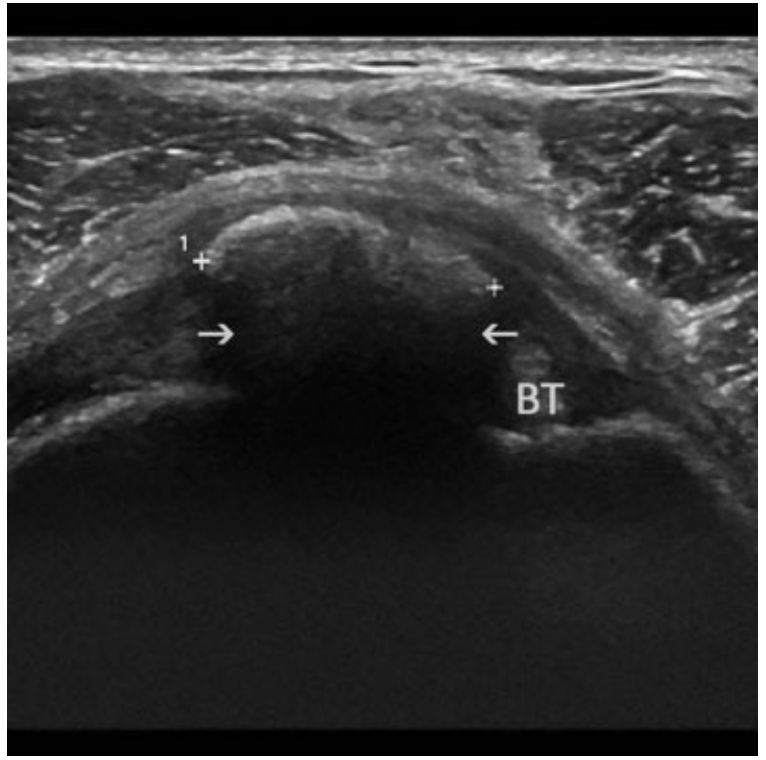

Fig. 6 Long axis US image over subscapularis tendon shows macrocalcification with posterior acoustic shadowing (arrows). BT, biceps tendon.

\section{Findings in the Cuff Tendons}

Rotator cuff pathology seen with US includes tendinopathy, calcific tendonitis, and partial-thickness and full-thickness tendon tears. Tendinopathy, that is, a thickened hypoechoic heterogeneous tendon on US, is often associated with thickening of the SASD bursa.

Calcification within the tendon ranges from small micro deposits, with no acoustic shadowing, to large deposits $(>1 \mathrm{~cm})$ of calcium hydroxyapatite, with shadowing (-Fig. 6). Macroscopic deposits are thought to go through phases of hard (marked acoustic attenuation) to soft (subtle shadowing) texture, which affects their susceptibility to USguided needle aspiration. The "soft" phase is typically very painful and may be associated with neovascularity. ${ }^{18}$

Partial-thickness tears are diagnosed when a focal hypoechoic defect is seen within the tendon affecting only a portion of the tendon thickness extending to either the bursal or articular surface, but not the full thickness of the tendon. The hypoechoic defect should be seen in two perpendicular planes. Secondary signs of partial-thickness tear include loss of the bursal surface convexity or tendon flattening, herniation of the deltoid muscle or bursa with transducer pressure, and cortical irregularity of the greater tuberosity. The depth or the grade of the tear should be recorded; grade $1: 3 \mathrm{~mm}$, grade 2: 3 to $6 \mathrm{~mm}$, grade 3:>6 mm. The location (bursal or articular sided) and the size of the tear should also be reported.

A full-thickness tear comprises a hypoechoic defect in the tendon that extends from the bursal to the articular surface of the tendon but does not need to involve the full width of the tendon. Other signs of a full-thickness tear include uncovered cartilage of the humeral head, compressible hypoechoic fluid or granulation tissue within the tendon gap, and herniation of the deltoid muscle or subacromial bursa into the gap. Secondary signs of a full-thickness tendon tear include cortical irregularity of the greater tuberosity and glenohumeral joint effusion. ${ }^{7}$ As mentioned, a full-thickness tear does not need to involve the complete width of the tendon, and therefore the location within the tendon and size of the tear should be described. Most tears affect the supraspinatus tendon especially the anterior free edge, adjacent to the rotator interval or the central area termed the midsubstance/ crescent/footprint where there is intact tendon anterior and posterior to the tear, possibly reflecting intact rotator cables. The tear most commonly affects the lateral $1.5 \mathrm{~cm}$ of the tendon in the hypovascular or "critical zone." The size of a tear should be described in two planes and are sometimes graded into as small: $<1 \mathrm{~cm}$; medium: 1 to $3 \mathrm{~cm}$; large: 3 to $5 \mathrm{~cm}$, and massive: $>5 \mathrm{~cm}$. If possible the extent of tendon retraction should be reported, but in massive tears this may be beyond the AC joint and therefore not visualized.

Other types of partial-thickness tendon tears that should be recognized are those that involve the rotator cuff footprint at the greater tuberosity. This is especially important in the younger patient or athlete because they can progress to fullthickness tears. These partial-thickness tears are described as a rim rent or partial articular-sided supraspinatus tendon avulsion (PASTA) lesions, and, as the name suggests, they involves tendon fibers being avulsed from the greater tuber-

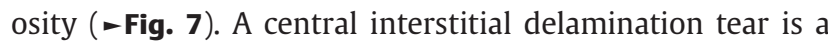
focal hypoechoic defect that does not reach the articular or bursal surface but parallels the long axis of the tendon. These tears may be recognized when a "cyst" is seen within the muscle or musculotendinous junction.

The accuracy of US in making these assessments has been well studied in the literature; accuracy is highest at the more extreme end of the pathologic range, reaching $100 \%$ for large tears, and lowest when only tendinopathy is present. Interand intraobserver variation is also highest with tendinopathy, reflecting the range of appearance of the normal tendon in the general population. When bursitis and tendinopathy

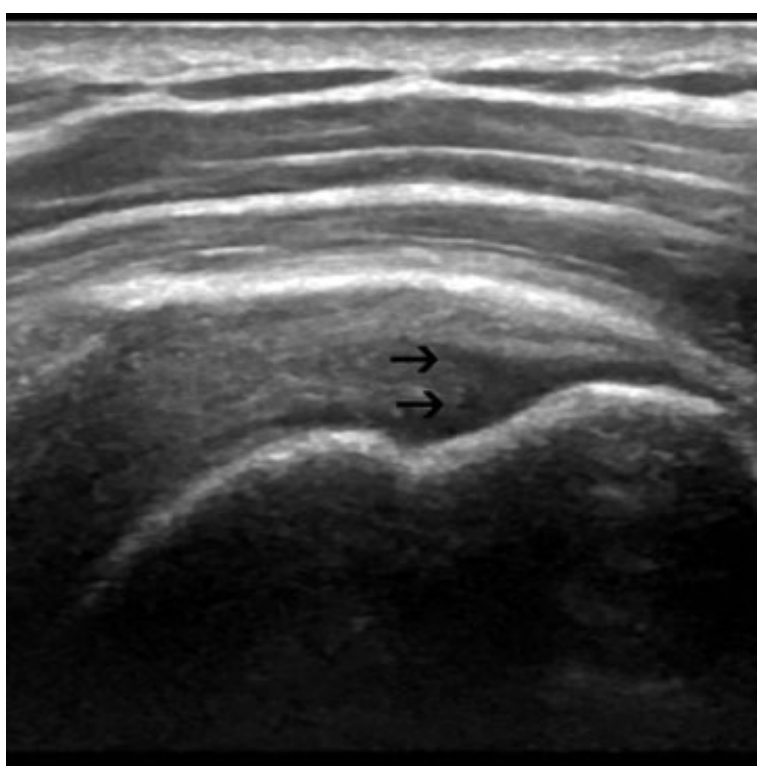

Fig. 7 Long axis view over supraspinatus tendon insertion on the humeral head demonstrates a rim-rent-type partial tear (arrows). 
coexist, it is also sometimes difficult to differentiate the superficial swollen hypoechoic aspect of the tendon and the thickened subacromial subdeltoid bursa on static imaging. It is also difficult to differentiate between tendinopathy and small partial-thickness tears because both give a hypoechoic appearance and may coexist. A recent meta-analysis reported pooled results of 0.95 (0.90 to 0.97 ) sensitivity and 0.96 ( 0.93 to 0.98 ) for specificity. For partial-thickness tears this is reduced: 0.72 ( 0.58 to 0.83 ) sensitivity and 0.93 ( 0.89 to $0.96)$ specificity. ${ }^{19-21}$

In the presence of a rotator cuff tear, assessment of the degree of fatty infiltration and atrophy of the supraspinatus muscle can be made. Assessment of substantial supraspinatus and infraspinatus fatty atrophy using US criteria has been shown to be moderately accurate and comparable with MR imaging. ${ }^{22}$ The US criteria used two scoring systems. The first graded conspicuity of muscle fibers, pennate architecture, and contour against the central tendon: grade $0=$ normal, grade 1 = partially visualized, and grade $2=$ discrete structures no longer visible. The second assessment compared the echogenicity of the rotator cuff muscle with deltoid, scoring grade 0 = isohypoechoic to deltoid, grade $1=$ slightly hyperechoic, and grade 2 = markedly more hyperechoic to deltoid. Significant atrophy was diagnosed if either system scored grade 2, which correlated to an MR imaging grade of 2 to 4 (Goutallier et al classification ${ }^{23}$ ).
The presence of neovascularity as a potential mechanism of pain production has been suggested in other tendinopathic tendons, although this is less often seen in the rotator cuff. Neovascularity in rotator cuff tendinopathy has been shown in the symptomatic and in the asymptomatic shoulder in a small group of patients. Further research is required to establish the relationship between neovascularity and the evolution of symptoms. ${ }^{24}$

\section{Tertiary Shoulder Impingement}

Taranu et $\mathrm{al}^{25}$ published an article in 2010 citing sternoclavicular (SC) joint arthritis as an unrecognized cause of shoulder impingement (-Fig. 8). They presented five patients initially diagnosed with external impingement but were subsequently shown to have SC joint osteoarthritis on computed tomography (radiographs were not diagnostic), despite being clinically nontender to palpation. They proposed the mechanism that loss of the elevation and rotation at the clavicle reduces scapula mobility and causes the acromion to impinge on the subacromial tissues. The term tertiary impingement appears appropriate within the external impingement classification. All five patients had a positive "shrug" test ${ }^{26}$ : inability to elevate/shrug the shoulder due to loss of the 35 degrees of elevation afforded by the clavicle at the SC joint. The authors point out that patients with massive rotator cuff tears also have a positive shrug sign, but the scanning radiologist would be aware of this
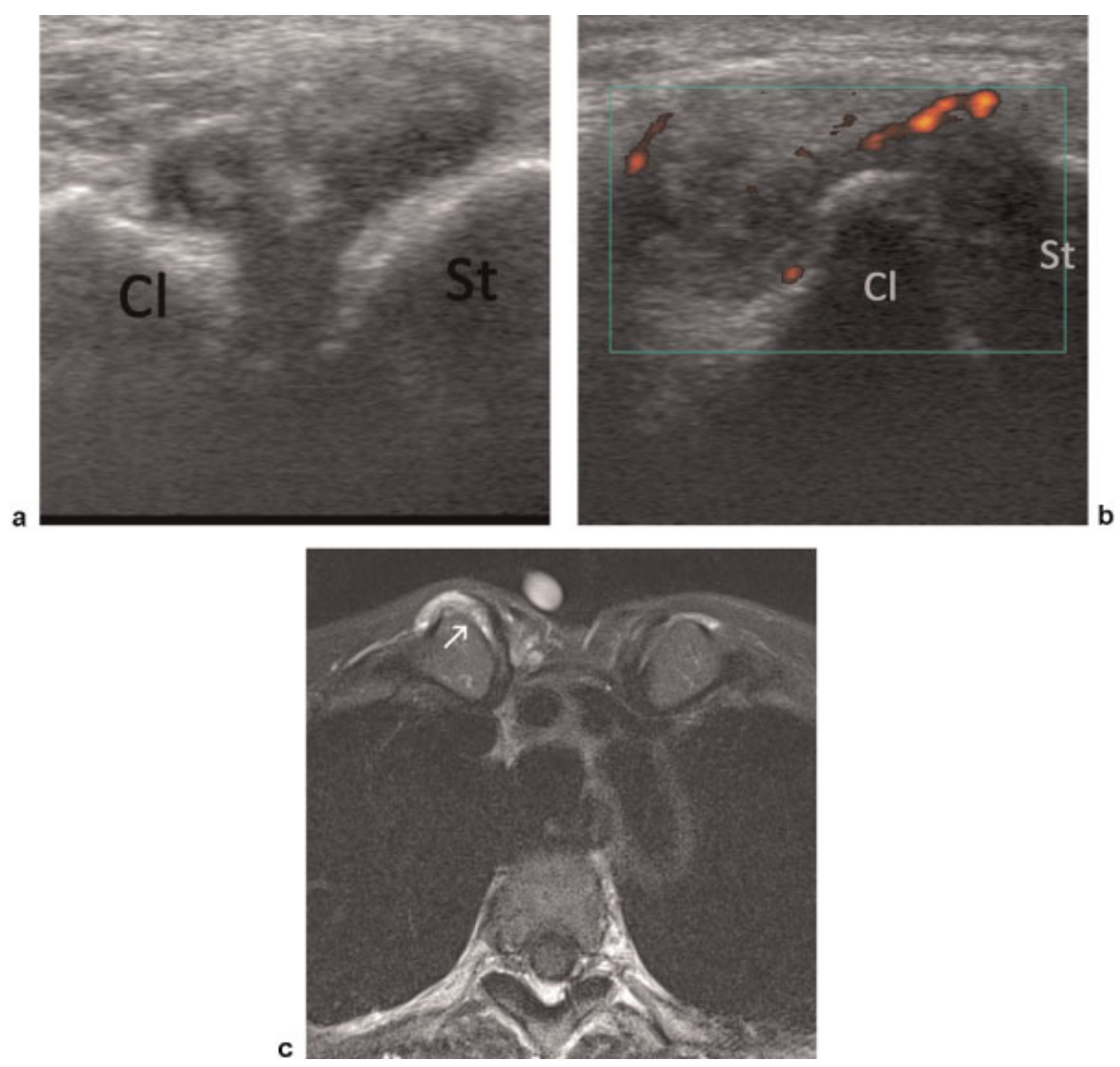

Fig. 8 Axial images across the sternoclavicular joint with (a) US, (b) power Doppler US, and (c) T2-weighted MRI, with skin marker, demonstrating a sternoclavicular joint (SCJ) arthropathy. White arrow shows right $\mathrm{SC}$ J effusion. Cl, clavicle; St, sternum. 
8 Shoulder Impingement Tagg et al.

Table 1 Injury patterns implicated in posterosuperior impingement

\begin{tabular}{|l|l|l|}
\hline Bone & Posterior glenoid rim and humeral head & Sclerosis/cyst formation \\
\hline Rotator cuff & Posterior supraspinatus/infraspinatus & Undersurface tear \\
\hline Joint capsule & Posterior & Thickening \\
\hline IGHL & Posterior band & Thickened \\
\hline IGHL & Anterior band & Stretched \\
\hline Labrum & Posterior & Type 2 SLAP lesion \\
\hline
\end{tabular}

Abbreviations: IGHL, inferior glenohumeral ligament; SLAP, superior labrum anterior and posterior.

Source: Adapted from Grainger, ${ }^{3}$ Jobe, ${ }^{28}$ and Castagna et al. ${ }^{30}$

from their US examination. Four of the five patients had a positive response to excision of the medial end of the clavicle and the fifth from physiotherapy without surgery. Because US is so adept at detecting joint erosion, the addition of SC joint evaluation could readily be added to the routine shoulder US assessment. As with many shoulder US findings, osteoarthritis at this joint is common, increases with age, and is often bilateral. $^{27}$ However, Taranu and colleagues recommended the routine use of the shrug test in the clinical evaluation of the shoulder. Perhaps as radiologists, we should add SC joint imaging to our shoulder US examination.

\section{Internal Impingement}

Whereas external impingement pathology is centered around the coracoacromial arch, internal impingement relates to the glenoid and labrum. Two distinct sites of pathology are described. Posterosuperior internal impingement results from impingement of the soft tissues (rotator cuff and posterior capsule) between the humeral head, cuff tendons, labrum, and glenoid. ${ }^{8}$ Anterosuperior internal impingement syndromes are a result of impingement of the soft tissues (rotator cuff, long head of biceps) on the anterior glenoid. $5,6,28$

Internal impingement is now recognized as an important source of pain, particularly in younger people. ${ }^{8}$ Much of the published work has been with overhead athletes and is a primary cause of chronic shoulder pain in this group. These athletes evolve their shoulder movement to maximize their external rotation, but this scenario is applicable to anyone frequently adopting an abducted and externally rotated position. $^{29}$

\section{Posterosuperior Impingement}

The etiology of these injuries is an evolving field, consolidated by Castagna et al in their review article. ${ }^{30}$ Concepts include the following:

1. Glenohumeral internal rotation deficit (GIRD) and "total arc of motion" 31 : Net range of motion at the shoulder does not change, but external rotation increases at the expense of internal rotation and posterior capsular contracture, shifting the contact point of the glenohumeral joint posterosuperior, resulting in a pseudolaxity of the anterior capsule. This in turn increases the peel-back forces on the superior labrum. ${ }^{32}$
2. Peel-back phenomenon: The shift in angle that occurs to the biceps anchor in external rotation and abduction, increasing torsional force on the labrum. ${ }^{33}$

3. Microinstability: Rotational or directional, pathologic laxity of the joint without frank dislocation, hypothesized by
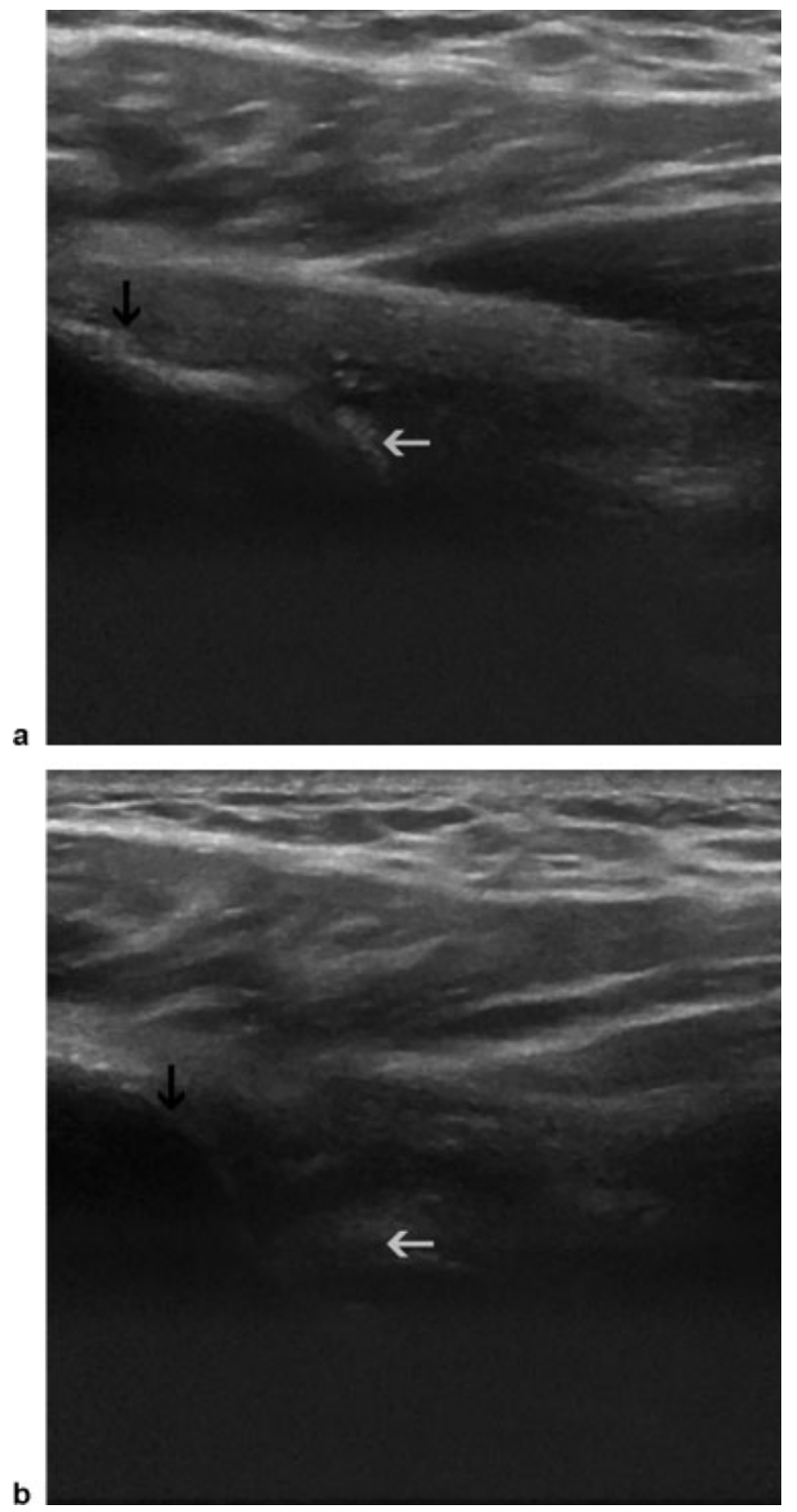

Fig. 9 Axial US images of posterior glenohumeral joint with increasing abduction and external rotation from position (a) to (b). White arrow shows labrum; black arrow shows greater tuberosity of humeral head. 
Table 2 Injury patterns implicated in anterosuperior impingement

\begin{tabular}{|l|l|l|}
\hline Rotator cuff & Subscapularis and anterior supraspinatus & Partial tears \\
\hline Long head of biceps & Tendon & Medial subluxation tendinopathy \\
\hline & Pulley & Tear \\
\hline Labrum & Anterior & Type 1 and 2 tears \\
\hline
\end{tabular}

Source: Adapted from Grainger. ${ }^{3}$

Paley et al. ${ }^{34}$ This loss of anterior stability is seen in overhead throwing athletes. $^{34}$

4. Scapular dyskinesis: Altered scapular motion in association with arm motion, as a result of muscle imbalances, resulting in excessive glenohumeral angulation, exacerbating peel-back effect and posterior impingement. ${ }^{33}$

The fact that these theories are interlinked and evolving, with impact on both external and internal impingement, is testament to the complex nature of the glenohumeral joint function and pathology. The diagnosis of these phenomena is largely clinical. - Table 1 shows the types of injury implicated in posterosuperior impingement.

\section{Ultrasound Findings}

It is acknowledged that much of this pathology cannot be evaluated with US. However, as previously discussed, fulland partial-thickness tears can be detected in the hands of an experienced operator. ${ }^{35,36}$ MR arthrogram remains the superior technique for the accurate diagnosis of partial tears. ${ }^{36}$ The role of US is currently limited to detecting asymmetric posterior joint capsular thickening and humeral retroversion suggesting GIRD: Thomas et al studied 24 collegiate baseball players, and they found humeral retroversion and posterior capsular thickness to be increased in the dominant arm. ${ }^{37}$ They used an inclinometer along the ulna border to measure retroversion, in conjunction with US of the bicipital groove, but one could see how this could be extrapolated as a comparative subjective measurement during a dynamic shoulder US examination. The relationship of the posterosuperior labrum and humeral head can also be visualized during simulated throwing maneuvers (-Fig. 9).

\section{Anterosuperior Impingement (ASI)}

The mechanism is of injury with anterosuperior impingement is the reverse of posterosuperior impingement: impingement occurs in horizontal adduction and internal rotation, impinging the biceps pulley and subscapularis tendon between the humeral head and the anterosuperior glenoid rim. ${ }^{2,3,6}$ Habermeyer ${ }^{6}$ et al. indicated that tears in these structures start a circle of impingement/tear. The cycle he proposed is demonstrated in - Fig. 10. The injury patterns implicated in anterosuperior impingement are listed in -Table 2.

\section{Ultrasound Findings}

Once again, these patterns are most comprehensively evaluated with MR arthrography, but US is highly specific and sensitive for the dynamic evaluation of biceps subluxation. ${ }^{38,39}$ This may occur in conjunction with thinning/tearing of the anterior rotator cuff, which can also be appreciated on US; however, small undersurface tears of the subscapularis are difficult to detect on US. ${ }^{3,40}$ Two studies found an association between anterosuperior impingement syndrome and acromioclavicular joint arthritis. ${ }^{2,6}$ Subcoracoid bursal collections are also associated with rotator interval disruption. ${ }^{41}$ US has a limited role in internal impingement, but recognizing the patterns of injury visible with US is important to ensure that MR arthrogram is recommended.

\section{Treatment}

Injection of SASD bursa with steroid and local anesthetic is often used to help with the diagnosis and treatment of external impingement; however, it is not clear whether it is the physical effect of bursal distension, the steroid, or placebo

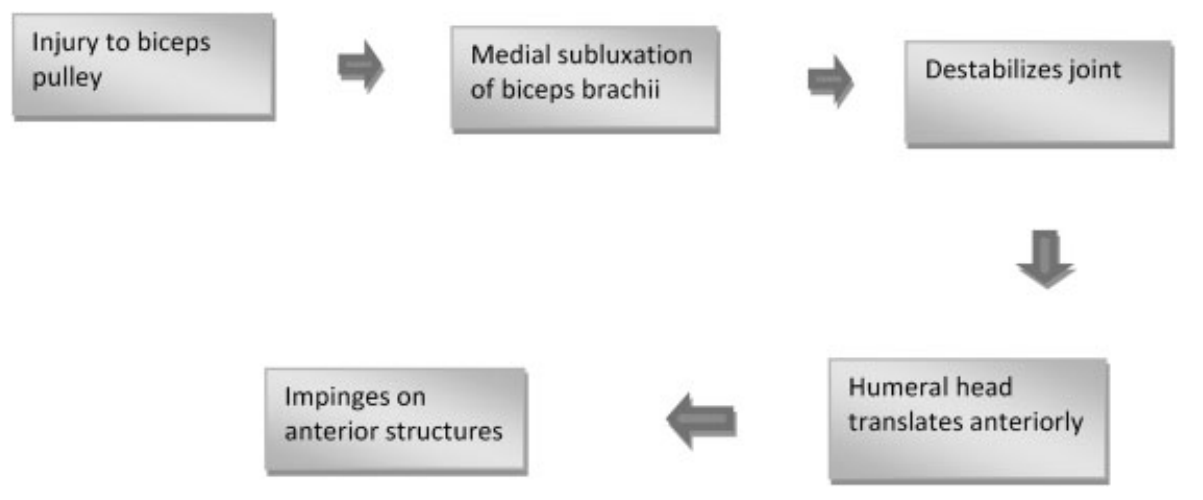

Fig. 10 Proposed mechanism of pathology in anterosuperior impingement. 

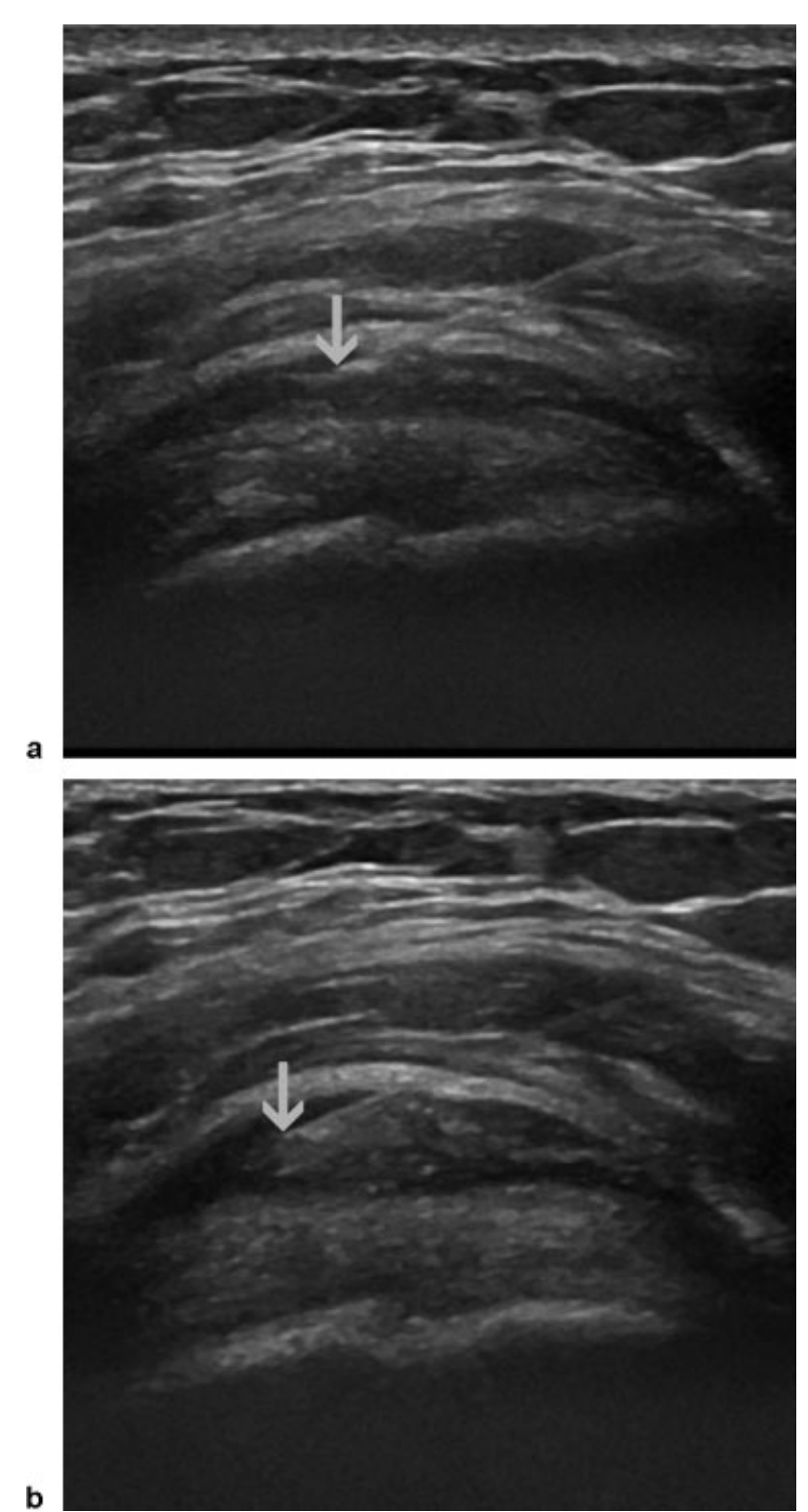

Fig. 11 Long axis US over supraspinatus shows gradual distension between (a) and (b) of the subacromial-subdeltoid bursa with steroid and local anesthetic solution. Arrow shows tip of needle in bursa.

effect that produces the symptomatic benefit in "injection responders" (- Fig. 11). ${ }^{17}$

In our institution, the patient is issued with a pain diary that charts their symptoms on a visual analog scale. Further lifestyle questions regarding daily activities, analgesia use, and perceived benefit are also included with the questionnaire. If there is significant acromioclavicular joint degenerative change, and the patient is predominantly tender here, a small volume of steroid and local anesthetic can be injected and a pain diary issued. The confounding evidence against this frequently performed intervention was reported by Ekeberg et al, who reported that gluteal injections of steroid were as effective as US-guided bursal injections. ${ }^{42}$ This was a heterogeneous population, however, and undervalued the role of a local anesthetic injection into the bursa as a diagnostic test.

\section{Conclusion}

Shoulder US has evolved into a dynamic clinical examination. Detecting impingement on US may be direct, as for external impingement, or recognizing patterns and subtle markers in internal impingement, while appreciating the limitations of US in internal glenohumeral joint assessment. Including acromioclavicular and sternoclavicular joint assessment may also be useful, although the reliability and usefulness of the latter has yet to be evaluated. The clinical correlation remains essential given the degree of pathology demonstrated in asymptomatic shoulders. Diagnostic and therapeutic US-guided local anesthetic and steroid injections continue to be used in their management.

\section{References}

1 Mayerhoefer ME, Breitenseher MJ, Wurnig C, Roposch A. Shoulder impingement: relationship of clinical symptoms and imaging criteria. Clin J Sport Med 2009;19(2):83-89

2 Gerber C, Sebesta A. Impingement of the deep surface of the subscapularis tendon and the reflection pulley on the anterosuperior glenoid rim: a preliminary report. J Shoulder Elbow Surg 2000;9(6):483-490

3 Grainger AJ. Internal impingement syndromes of the shoulder. Semin Musculoskelet Radiol 2008;12(2):127-135

4 Campbell RS, Dunn A. External impingement of the shoulder. Semin Musculoskelet Radiol 2008;12(2):107-126

5 Jobe FW, Kvitne RS, Giangarra CE. Shoulder pain in the overhand or throwing athlete. The relationship of anterior instability and rotator cuff impingement. Orthop Rev 1989;18(9):963-975

6 Habermeyer P, Magosch P, Pritsch M, Scheibel MT, Lichtenberg S. Anterosuperior impingement of the shoulder as a result of pulley lesions: a prospective arthroscopic study. J Shoulder Elbow Surg 2004;13(1):5-12

7 Neer CS II. Anterior acromioplasty for the chronic impingement syndrome in the shoulder: a preliminary report. J Bone Joint Surg Am 1972;54(1):41-50

8 Walch G, Liotard JP, Boileau P, Noël E. Postero-superior glenoid impingement. Another impingement of the shoulder [in French]. J Radiol 1993;74(1):47-50

9 Bigliani LU, Morrison DS, April EW. The morphology of the acromion and its relation to rotator cuff tears. Orthop Trans 1986;10:228

9a Burkhart SS, Morgan CD, Kibler WB. The disabled throwing shoulder: spectrum of pathology. Part III: the SICK scapula, scapula dyskinesis, the kinetic chain, and rehabilitation. Arthroscopy 2003;19:641-661

10 Papadonikolakis A, McKenna M, Warme W, Martin BI, Matsen FA III. Published evidence relevant to the diagnosis of impingement syndrome of the shoulder. J Bone Joint Surg Am 2011;93 (19):1827-1832

11 Holsbeeck MV, Strouse P. Sonography of the shoulder: evaluation of the subacromial subdeltoid bursa. AJR Am J Roentgenol 2003;160:561-564

12 Hollister MS, Mack LA, Patten RM, Winter TC III, Matsen FA III, Veith RR. Association of sonographically detected subacromial/ subdeltoid bursal effusion and intraarticular fluid with rotator cuff tear. AJR Am J Roentgenol 1995;165(3):605-608

13 Daghir AA, Sookur PA, Shah S, Watson M. Dynamic ultrasound of the subacromial-subdeltoid bursa in patients with shoulder impingement: a comparison with normal volunteers. Skeletal Radiol 2012;41(9):1047-1053

14 Wang YC, Wang HK, Chen WS, Wang TG. Dynamic visualization of the coracoacromial ligament by ultrasound. Ultrasound Med Biol 2009;35(8):1242-1248 
15 Desmeules F, Minville L, Riederer B, Côté CH, Frémont P. Acromiohumeral distance variation measured by ultrasonography and its association with the outcome of rehabilitation for shoulder impingement syndrome. Clin J Sport Med 2004;14(4):197-205

16 Bureau NJ, Beauchamp M, Cardinal E, Brassard P. Dynamic sonography evaluation of shoulder impingement syndrome. AJR Am J Roentgenol 2006;187(1):216-220

17 Silva RT, Hartmann LG, Laurino CF, Biló JP. Clinical and ultrasonographic correlation between scapular dyskinesia and subacromial space measurement among junior elite tennis players. Br J Sports Med 2010;44(6):407-410

17a Wu C-H, Lin C-M, Wang Y-C, Wang T-G, Wang Y-H. Reduced displacement of the coracoacromial ligaments during shoulder motion in the aged: evaluation by ultrasonography. J Med Ultrasound 2010;18:124-129

18 Uhthoff HK, Loehr JW. Calcific tendinopathy of the rotator cuff: pathogenesis, diagnosis, and management. J Am Acad Orthop Surg 1997;5(4):183-191

19 Teefey SA, Hasan SA, Middleton WD, Patel M, Wright RW, Yamaguchi K. Ultrasonography of the rotator cuff. A comparison of ultrasonographic and arthroscopic findings in one hundred consecutive cases. J Bone Joint Surg Am 2000;82(4):498-504

20 Vlychou M, Dailiana Z, Fotiadou A, Papanagiotou M, Fezoulidis IV, Malizos K. Symptomatic partial rotator cuff tears: diagnostic performance of ultrasound and magnetic resonance imaging with surgical correlation. Acta Radiol 2009;50(1):101-105

21 Ottenheijm RP, Jansen MJ, Staal JB, et al. Accuracy of diagnostic ultrasound in patients with suspected subacromial disorders: a systematic review and meta-analysis. Arch Phys Med Rehabil 2010;91(10):1616-1625

22 Strobel K, Hodler J, Meyer DC, Pfirrmann CW, Pirkl C, Zanetti M. Fatty atrophy of supraspinatus and infraspinatus muscles: accuracy of US. Radiology 2005;237(2):584-589

23 Goutallier D, Postel JM, Bernageau J, Lavau L, Voisin MC. Fatty muscle degeneration in cuff ruptures. Pre- and postoperative evaluation by CT scan. Clin Orthop Relat Res 1994;(304): 78-83

24 Lewis JS, Raza SA, Pilcher J, Heron C, Poloniecki JD. The prevalence of neovascularity in patients clinically diagnosed with rotator cuff tendinopathy. BMC Musculoskelet Disord 2009;10:163

25 Taranu R, et al. Sternoclavicular joint arthritis: unrecognised cause of shoulder impingement. Shoulder and Elbow 2010;2: 156-160

26 Chaitow L. Palpation and assessment skills: assessment and diagnosis through touch. 2nd ed. Vol 29. Edinburgh, United Kingdom: Churchill Livingstone; 2003

27 Yood RA, Goldenberg DL. Sternoclavicular joint arthritis. Arthritis Rheum 1980;23(2):232-239
28 Jobe CM. Superior glenoid impingement. Current concepts. Clin Orthop Relat Res 1996;(330):98-107

29 Kaplan LD, McMahon PJ, Towers J, Irrgang JJ, Rodosky MW. Internal impingement: findings on magnetic resonance imaging and arthroscopic evaluation. Arthroscopy 2004;20(7): 701-704

30 Castagna A, Garofalo R, Cesari E, Markopoulos N, Borroni M, Conti M. Posterior superior internal impingement: an evidence-based review [corrected]. Br J Sports Med 2010;44(5):382-388

31 Wilk KE, Meister K, Andrews JR. Current concepts in the rehabilitation of the overhead throwing athlete. Am J Sports Med 2002; 30(1):136-151

32 Burkhart SS, Morgan CD. The peel-back mechanism: its role in producing and extending posterior type II SLAP lesions and its effect on SLAP repair rehabilitation. Arthroscopy 1998;14(6): 637-640

33 Abrams GD, Safran MR. Diagnosis and management of superior labrum anterior posterior lesions in overhead athletes. Br J Sports Med 2010;44(5):311-318

34 Paley KJ, Jobe FW, Pink MM, Kvitne RS, ElAttrache NS. Arthroscopic findings in the overhand throwing athlete: evidence for posterior internal impingement of the rotator cuff. Arthroscopy 2000; 16(1):35-40

35 Beggs I. Shoulder ultrasound. Semin Ultrasound CT MR 2011; 32(2):101-113

36 de Jesus JO, Parker L, Frangos AJ, Nazarian LN. Accuracy of MRI, MR arthrography, and ultrasound in the diagnosis of rotator cuff tears: a meta-analysis. AJR Am J Roentgenol 2009;192(6):1701-1707

37 Thomas SJ, Swanik CB, Kaminski TW, et al. Humeral retroversion and its association with posterior capsule thickness in collegiate baseball players. J Shoulder Elbow Surg 2012;21(7):910-916

38 Ejnisman B, Monteiro GC, Andreoli CV, de Castro Pochini A. Disorder of the long head of the biceps tendon. Br J Sports Med 2010;44(5):347-354

39 Armstrong A, Teefey SA, Wu T, et al. The efficacy of ultrasound in the diagnosis of long head of the biceps tendon pathology. J Shoulder Elbow Surg 2006;15(1):7-11

40 Teefey SA, Middleton WD, Payne WT, Yamaguchi K. Detection and measurement of rotator cuff tears with sonography: analysis of diagnostic errors. AJR Am J Roentgenol 2005;184(6):1768-1773

41 Grainger AJ, Tirman PF, Elliott JM, Kingzett-Taylor A, Steinbach LS, Genant HK. MR anatomy of the subcoracoid bursa and the association of subcoracoid effusion with tears of the anterior rotator cuff and the rotator interval. AJR Am J Roentgenol 2000;174(5):1377-1380

42 Ekeberg OM, Bautz-Holter E, Tveitå EK, Juel NG, Kvalheim S, Brox JI. Subacromial ultrasound guided or systemic steroid injection for rotator cuff disease: randomised double blind study. BMJ 2009;338:a3112 